This document is the accepted manuscript version of the following article:

Priebe, A., Xie, T., Bürki, G., Pethö, L., \& Johann, M. (2020). Matrix effect in TOF-SIMS analysis of two-element inorganic thin films. Journal of Analytical Atomic spectrometry. https://doi .org/10.1039/C9JA00428A

\title{
ARTICLE
}

\section{Matrix effect in TOF-SIMS analysis of two-element inorganic thin films}

Received 00th January 20xx, Accepted 00th January 20xx

DOI: $10.1039 / \times 0 \times x 00000 x$

\author{
Agnieszka Priebe ${ }^{*}, \mathrm{a}$, Tianle Xie ${ }^{\mathrm{a}, \mathrm{b}}$, Gerhard Bürkia, Laszlo Pethöa and Johann Michler ${ }^{\mathrm{a}}$
}

\begin{abstract}
Matrix effect, i.e. the dependence of element ion yield on the surrounding chemical state, is very often considered as a negative and limiting factor in elemental characterization. In fact, it is the main reason making Time-of-Flight Secondary lon Mass Spectrometry (TOF-SIMS) a non-quantitative technique as element ionization efficiency can span over several orders of magnitude depending on the matrix. Despite that, even small chemical variations of an experimental setup can cause interpretation of TOF-SIMS depth profiles a challenging task. However, the sensitivity of element ionization to the neighboring atoms can be also very beneficial as ion yields can be enhanced in the presence of particular species such as oxygen, cesium, water and fluorine. In this work, we make an attempt to estimate the matrix effect in two-element Zrcontaining alloys using TOF-SIMS. The $\mathrm{Zr}$ ionization efficiency as well as its response to the surface and interface contaminants was investigated depending on Al, Si and Cu matrixes. It was observed that Zr ionization efficiency is over four times higher in the Si matrix than in the Cu matrix and over two times higher when compared to the results obtained in the Al matrix.
\end{abstract}

\section{Introduction}

In Time-of-Flight Secondary Ion Mass Spectrometry (TOF-SIMS) ${ }^{1}$ secondary species are ejected from a sample surface due to the primary ion beam bombardment. Only a small fraction of the entire sputtered population is ionized and, therefore, can be guided towards a mass analyser and be detected. The ionisation process is strongly affected by solid's surface chemistry and surface modifications associated with the sputtering process (so called matrix effect ${ }^{2-4}$ ). Moreover, the response of elements to the surrounding matter is very specific, i.e. at the same experimental conditions the ion yield of one element can be enhanced whilst the ion yield of another element can be decreased. As a consequence of the matrix effect the efficiency of secondary ions generation can span over five orders of magnitude or even more causing TOF-SIMS a non-quantitative technique. This can make acquired data difficult to interpret, especially in the case of biological samples ${ }^{5,6}$. Matrix effect can also affect the quality of multilayer inorganic depth profiles leading to the presence of secondary ion signal peaks (mainly due to the surface oxidation) within several sputtered scans 7,8 . The signal peaks can be also observed in the vicinity of sample interfaces and on the interface between the sample and the substrate. In the latter case, the measured elemental signal can

\footnotetext{
a. Empa, Swiss Federal Laboratories for Materials Science and Technology, Laboratory for Mechanics of Materials and Nanostructures, Feuerwerkerstrasse 39, $\mathrm{CH}-3602$ Thun, Switzerland.

b. College of Material Science and Engineering, Hunan University, 2 Lushan S Rd, Yuelu, Changsha, 410082, P.R. China.

*Corresponding author: agnieszka.priebe@empa.ch
}

be influenced by the substrate elements and/or potential substrate oxidation.

Several solutions to the problem of matrix effect (both, on the level of conducting TOF-SIMS measurements and on the data analysis stage) are reported in literature. $\mathrm{MCs}^{+}$technique, which is based on measuring a molecular ion composed of an ion of interest, $\mathrm{M}$, and an ion originating from a $\mathrm{Cs}$ analysis beam ${ }^{9}$ instead of measuring the ionized atom $\mathrm{M}^{+}$directly, allows the matrix effect to be reduced ${ }^{10}$. Promising results were also observed in the case of substituting $\mathrm{MCs}^{+}$with $\mathrm{MCs}^{2+}$ (for electronegative elements) and $\mathrm{MA}^{+}$(A stands for alkali primary ion and denotes $\mathrm{K}^{+}, \mathrm{Rb}^{+}$and $\mathrm{Na}^{+}$). Depositing a silver layer (MetA-SIMS, i.e. metal-assisted SIMS) before the TOF-SIMS analysis was found to reduce the matrix effect in organic materials on silicon and polypropylene substrates ${ }^{11}$. Apart from that, it was demonstrated that the use of a water cluster beam helps reducing the matrix effect present in amino acids combined with trehalose ${ }^{12}$. The surface chemistry can be deconvoluted ${ }^{13}$ from matrix effect using Principal Components Analysis (PCA) ${ }^{14-16}$ during the data processing.

On the other hand, matrix effect can be also very beneficial for elemental characterization of specimens. It was proved in many publications that incorporating oxygen $2,17,18$, water ${ }^{8,19-21}$ or fluorine compounds (such as $\mathrm{SF}_{\mathrm{m}}{ }^{22,23}$ or $\mathrm{XeF}_{2}{ }^{8,24}$ ) to an experimental setup can significantly enhance positive ion yields whilst using caesium ${ }^{2,25-31}$ improves generation of negative ions.

Although the existence of matrix effect and its importance for elemental analysis are beyond a shadow of a doubt, still its driving mechanisms are not explored and well-understood. A unified explanation for secondary ion yields proposed by Deline ${ }^{32}$ was critically analysed by Witmaack ${ }^{33}$. The dispute on 
ion-yield matrix effects was continued by Williams ${ }^{34}$. This is a great example that unification of ion-yield phenomena is not trivial despite operating with complex theoretical formulas and a broad scope of experimental data. A comprehensive review of ion emission models (i.e. the "bond-breaking" model, work function model, band structure model, molecular model and surface-polarization model) is provided by Williams 35. However, none of these theoretical apparatuses is sufficiently supported by experimental evidences to provide the desired level of accuracy in predicting secondary ion yields.

To the best of our knowledge, no systematic studies of ionization probability were conducted on complex metallic materials under continuous bombardment of a $\mathrm{Ga}^{+}$primary ion beam. Therefore, we address this publication to investigating the matrix effect in Zr-based two-element alloys under these conditions. The $\mathrm{Zr}$ ion yield (indirectly measured with a TOFSIMS signal) was examined as a dependence of another component (precisely: $\mathrm{Al}, \mathrm{Si}$ and $\mathrm{Cu}$ ) composing an alloy. It was observed that $\mathrm{Zr}$ ionisation efficiency was the highest in the presence of Si atoms (by a factor of 4.2 when compared to the results obtained for $\mathrm{ZrCu}$ sample and by a factor of 2.2 in comparison with $\mathrm{ZrAl}$ results). The sputtering rates of the alloys have varied between $0.65 \mathrm{~nm} /$ frame and $1.09 \mathrm{~nm} /$ frame at given experimental conditions. The results presented in this work are the second stage of our extended efforts targeted in exploring the potential and limitations of gas-assisted TOFSIMS $^{8}$ which can lead to significant improvement of elemental image quality and separation of mass interference ${ }^{24}$. In order to verify the influence of water vapour and fluorine gas on the ionization process of two-element alloys, first the generation of secondary ions in standard vacuum conditions has to be known.

\section{Experimental}

\section{Materials}

A choice of proper elements for studying the matrix effect is a challenging task even in the case of simplified systems such as two-element model samples. First of all, ion yields of individual elements have to be sufficiently high to appear in a TOF-SIMS mass spectrum. Preferably, their depth profiles should be constant in time and without statistical fluctuations. Moreover, specimen components should not mass-interfere, i.e. neither their isotopes nor oxides/hydrides should have the same or similar masses. Finally, the two elements should be compatible so that they can mix efficiently. This is required to prevent material segregation, which can lead to preferential FIB sputtering. In order to find the most appropriate candidates for the matrix effect studies, first a series of TOF-SIMS experiments was conducted on single-element metallic thin films of $\mathrm{Cu}, \mathrm{Zr}$, $\mathrm{Ag}$ and $\mathrm{W}^{8}$. Among these elements, $\mathrm{Zr}$ shows the highest (twothree orders of magnitude greater than the other elements) ion yield (indirectly measured with TOF-SIMS) and its depth profile has the most stable signal distribution in time. Therefore, $\mathrm{Zr}$ was chosen as an invariant base element for the matrix studies and other elements, i.e. Al, $\mathrm{Si}$ and $\mathrm{Cu}$, were used as variables. The choice of these elements was closely related to intense development of Bulk Metallic Glasses (BMG ${ }^{36-44}$ ) constituting novel type of materials which are apporphbus/Gandoquase excellent mechanical properties but become brittle under external stress. Among various types of BMGs, particularly interesting are Zr-based BMG alloys as they combine high strength, low Young's modulus and resistance to corrosion ${ }^{45}$. Therefore, they can find application in industry and medical applications ${ }^{46,47}$ (such as orthopaedic implants ${ }^{48}$ and vascular stents ${ }^{49}$ ). Besides that, other systems containing the elements investigated in this study are promising. Si-doped zirconium aluminate ( $\mathrm{Zr}-\mathrm{Al}-\mathrm{Si}-\mathrm{O})$ was proposed as a novel gate dielectric 50 which can be used in high temperature metal-gate complementary metal-oxide-semiconductor (CMOS ${ }^{51}$ ). Zr-Al$\mathrm{Cu}$ and $\mathrm{Zr}-\mathrm{Al}-\mathrm{Cu}-\mathrm{Ni}$ amorphous alloys are expected to be used for fine parts in microelectromechanical systems ${ }^{52}$ (MEMS ${ }^{53}$ ). $\mathrm{Zr}$-rich aluminates are also considered as promising candidates for high permittivity gate dielectric applications ${ }^{54}$. (Zr-Al)codopoing can improve visible light photocatalytic properties of $\mathrm{ZnO}{ }^{55}$. Incorporating Al to $\mathrm{Cu}-\mathrm{Zr}$ alloys changes glass-forming ability (GFA) 56 which can lead to improving mechanical properties of these materials.

In summary, studies on matrix effect in Zr-based systems can provide important insights for understanding ionization processes. This can lead to better interpretation of TOF-SIMS data sets and, ultimately, can serve for future optimization of chemical composition of the novel materials to maximize their functionality.

The knowledge of FIB-sputtered volume of the matter is crucial for comparing TOF-SIMS signals of various samples. Therefore, in these studies thin films were used as (in contrast to bulk materials) the amount of milled material can be directly obtained from TOF-SIMS depth profiles (i.e. the thin filmsubstrate interface can usually be well recognized) if the thickness of the sample is known. In this approach post-TOFSIMS measurements of a crater depth with Atomic Force Microscope $\left(\mathrm{AFM}^{57}\right)$ or Scanning Electron Microscopy (SEM ${ }^{58}$ ) are not necessarily needed.

A set of three model samples composed of two metals ( $\mathrm{ZrAl}$ and $\mathrm{ZrCu}$ ) and a metal-metalloid ( $\mathrm{ZrSi}$ ) forming alloys were produced using the Physical Vapour Deposition (PVD) ${ }^{59}$. 99.99\% purity Al, $\mathrm{Si}$ and $\mathrm{Zr}$ solid targets from Testbourne Ltd (Hampshire, England) and $99.99 \%$ purity $\mathrm{Cu}$ solid targets from EVOCHEM (Offenbach am Main, Germany) were used in a 3" sputter magnetron from MANTIS Deposition Ltd (Oxfordshire, United Kingdom) for depositing the thin films with the thickness in the order of $100 \mathrm{~nm}$ on $<100>$ single crystal Si wafers under the conditions summarized in Table 1 . The thin film deposition parameters were roughly adjusted to achieve 50 at. \% of $Z r$ in the alloys.

Additionally, the samples were coated with a $5 \mathrm{~nm}$ Au layer to prevent FIB-induced charging effects during the TOF-SIMS measurements. This solution (in combination with mounting a sample on a stub with a carbon tape and electric connections made using a silver paste) seems to be much more reliable than applying charge compensation with an electron beam during FIB sputtering as, to our experience, SEM beam instabilities can introduce artefacts to chemical depth profiles. 
Table 2. PVD parameters used for two-element thin film deposition.

\begin{tabular}{|c|c|c|c|c|c|c|}
\hline Sample & Target & Voltage [V] & $\begin{array}{c}\text { Current } \\
{[\mathrm{mA}]}\end{array}$ & Argon flow $[\mathrm{sccm}]$ & Base pressure [mbar] & $\begin{array}{c}\text { Process pressure } \\
{[\mathrm{mbar}]}\end{array}$ \\
\hline \multirow{2}{*}{ ZrAl } & $\mathrm{Zr}$ & 309 & 180 & \multirow{2}{*}{10} & \multirow{2}{*}{$2.6 \cdot 10^{-7}$} & \multirow{2}{*}{$5.2 \cdot 10^{-3}$} \\
\hline & $\mathrm{Al}$ & 360 & 100 & & & \\
\hline \multirow{2}{*}{$\mathrm{ZrSi}$} & $\mathrm{Zr}$ & 279 & 140 & \multirow{2}{*}{15} & \multirow{2}{*}{$1.9 \cdot 10^{-7}$} & \multirow{2}{*}{$7.0 \cdot 10^{-3}$} \\
\hline & $\mathrm{Si}$ & 495 & 60 & & & \\
\hline \multirow{2}{*}{$\mathrm{ZrCu}$} & $\mathrm{Zr}$ & 313 & 180 & \multirow{2}{*}{10} & \multirow{2}{*}{$9.0 \cdot 10^{-7}$} & \multirow{2}{*}{$5.2 \cdot 10^{-3}$} \\
\hline & $\mathrm{Cu}$ & 412 & 130 & & & \\
\hline
\end{tabular}
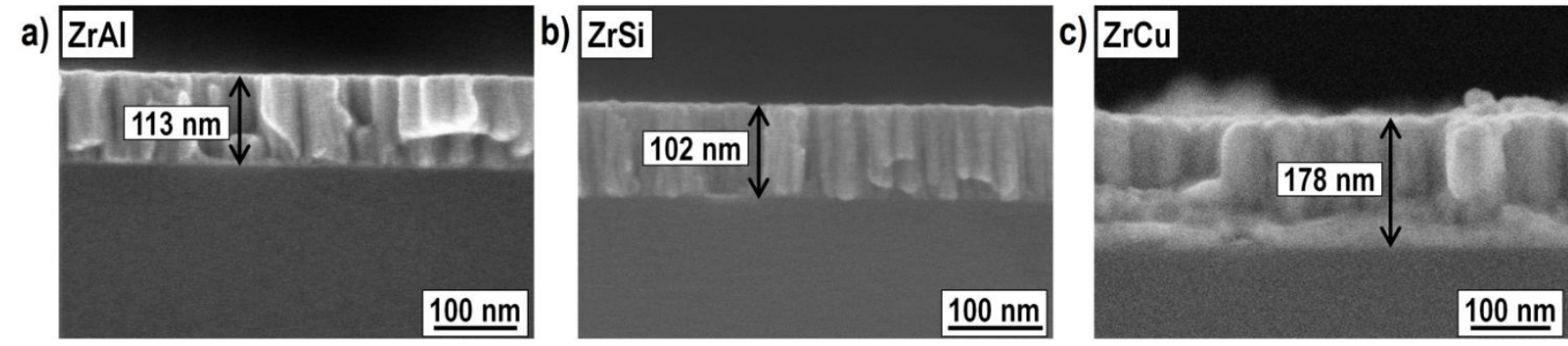

Figure 1. SEM images of samples' cross-sections: a) ZrAl, b) ZrSi and c) ZrCu.

\section{Methods}

The exact thicknesses of the thin films were measured on the sample cross-sections using a Hitachi (Tokyo, Japan) S-4800 high resolution Field Emission Scanning Electron Microscope (FESEM ${ }^{60}$ ).

The TOF-SIMS measurements on two-element alloys were conducted using a high vacuum-compatible CTOF detector (TOFWERK, Thun, Switzerland) integrated within FIB/SEM (Focused Ion Beam/Scanning Electron Microscope) Lyra3 dualbeam system from Tescan (Brno, the Czech Republic). The secondary ions were generated together with neutral atoms and molecules from the sample surface as the consequence of continuous FIB beam bombardment. However, only the charged species were guided by the applied electric field to the mass spectrometer and, therefore, were measured. The massto-charge range was determined by the time during which the FIB beam stays on a given pixel, i.e. the dwell time. A monoisotopic ${ }^{69} \mathrm{Ga}^{+}$beam at $20 \mathrm{keV}$ energy, $(115 \pm 3) \mathrm{pA}$ ion current, $10 \mu \mathrm{s} d$ well time and the aperture of $100 \mu \mathrm{m}$ was used for both, sputtering and imaging. The sample was located perpendicular to the FIB axis and on the intersection point between the ion beam and the electron beam. The data were acquired from 10 $\mu \mathrm{m} \times 10 \mu \mathrm{m}$ scan areas with $512 \times 512$ pixels and $2 \times 2$ binning in the positive ion detection mode. In order to avoid the crater edge artefacts, the data analysis ROls were limited to the central $5 \mu \mathrm{m} \times 5 \mu \mathrm{m}$ areas.

TOF-SIMS Explorer version 1.4.0.0 was used for the acquisition and analysis of the secondary ion signals. The data were masscalibrated with a primary ion beam signal peak $\left({ }^{69} \mathrm{Ga}^{+}\right)$, the substrate signal peak $\left({ }^{28} \mathrm{Si}^{+}\right)$, and signal peaks coming from the thin films $\left({ }^{90} \mathrm{Zr}^{+}\right.$and either ${ }^{27} \mathrm{Al}^{+}$or ${ }^{63} \mathrm{Cu}^{+}$, for $\mathrm{ZrAl}$ alloy and $\mathrm{ZrCu}$ alloy, respectively). The reported values of secondary ion signals represent data acquired for a given mass-to-charge-ratio of an ion, $m / Q$, within the $(1 \pm 0.5) m / Q$ range. This method allows the contribution of signal peak tails to be taken into account.

\section{Results and discussion}

Verification of the thin films deposition quality and FIB sputtering process

The main difficulty of studying matrix effect results from the imposed very strict experimental conditions including a proper sample handling. Due to the very high sensitivity of this technique, even small pressure variations in the vacuum chamber and the quality of the primary beam source can affect the magnitude of measured secondary ion signals. Therefore, all three samples were inserted to the FIB/SEM instrument together and all measurements were conducted within relatively short time (several hours). However, it has to be noted that local surface contaminations can also modify the secondary ion signal strength.

In order to compare absolute values of TOF-SIMS signals coming from different samples, the exact sputtered volumes have to be determined. Since FIB scan areas were set to $10 \mu \mathrm{m} \times 10 \mu \mathrm{m}$ for all experiments, the only parameter which can vary the samples is their thickness. The PVD deposition algorithms were applied during the sample preparation process to obtain the sample thicknesses in the order of $100 \mathrm{~nm}$. In addition, to assess the precise values the SEM measurements on sample cross-sections were conducted (Figure 1). The thicknesses of the layers, $h$, for $\mathrm{ZrAl}, \mathrm{ZrSi}$ and $\mathrm{ZrCu}$ were $h_{\mathrm{ZrAl}}=113 \mathrm{~nm}, h_{Z \mathrm{rSi}}=102 \mathrm{~nm}$ and $h_{\mathrm{ZrCu}}$ $=178 \mathrm{~nm}$, respectively.

Natural sample roughness as well as FIB-induced roughness of a crater bottom during a TOF-SIMS measurement can also influence depth profiles (due to a mixing of the thin film part with the substrate) which are used for calculating total secondary ion signals acquired from a given volume. Therefore, 
Figure 2. FIB SE images of the sample surfaces (ZrAl: a1-a3; ZrSi: b1-b3; ZrCu: c1-c3) during the FIB sputtering process. A1, b1, c1 upper-most surfaces of the samples; a2, b2, c2 - topology of the surfaces after milling a half of the thin films, a3, b3, c3 - topology of the thin film-substrate interfaces.

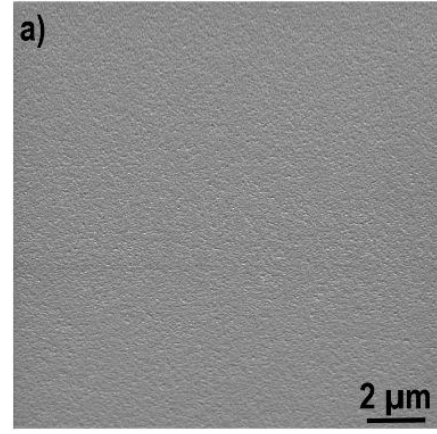

b)

Figure 3. Insitu SEM images of ZrCu sample surface before (a) and after (b) TOF-SIMS measurement. The shape of the crater indicates a correct FIB sputtering process.

the sample topology was imaged on-line during the FIB-TOFSIMS experiments using FIB SE (Secondary Electrons) images (Figure 2). Initial surface variations of $\mathrm{ZrAl}$ and $\mathrm{ZrCu}$ samples (Figure 2 a1 and $c 1$ ) were smoothen during the sputtering process (Figure 2 a2 and $\mathrm{c} 2$ ). In the case of $\mathrm{ZrSi}$ (Figure $2 \mathrm{~b} 1$ and b2) the sample topology was flat. Neither pores nor grains indicating material segregation were observed in any of the thin films. A regular contrast pattern (Figure $2 \mathrm{c3}$ ), which can be correlated with FIB-induced roughness, was observed on the thin film-substrate interface only in the case of $\mathrm{ZrCu}$ sample.
Nevertheless, the quality of FIB sputtering process has still ensured the precise estimations of the interface locations in all depth profiles.

Apart from the possibility of monitoring sample topology with FIB SE during a TOF-SIMS measurement, integrating a TOF detector within a FIB/SEM instrument allows a quality of a sputtered crater to be verified insitu without breaking vacuum conditions (which is usually not attainable in the case of dedicated TOF-SIMS instruments). The crater shape provides important information on the correctness of applied FIB parameters (i.e. the beam focus, $x$-stigmatism, $y$-stigmatism, beam centring in $x$ - and $y$-directions) and potential drift (which can introduce artefacts especially in the case of depth profiling). Figure 3 shows the $\mathrm{ZrCu}$ sample surface before (a) and after (b) FIB-TOF-SIMS measurement. The sharp crater edges indicate that the beam parameters were adjusted properly and the sputtering process was free from drift and charging effects. Similar results were obtained in the case of $\mathrm{ZrAl}$ and $\mathrm{ZrSi}$ samples.

The sensitivity of the TOF-SIMS technique is very high allowing even trace elements to be detected. Therefore, mass spectra (Figure 4) were used to verify purity of the samples. Apart from the main expected elements (i.e. $\mathrm{Zr}, \mathrm{Al}, \mathrm{Si}, \mathrm{Cu}$ and $\mathrm{Ga}$ ), only $\mathrm{ZrO}$ isotopes have given significantly high signals. 

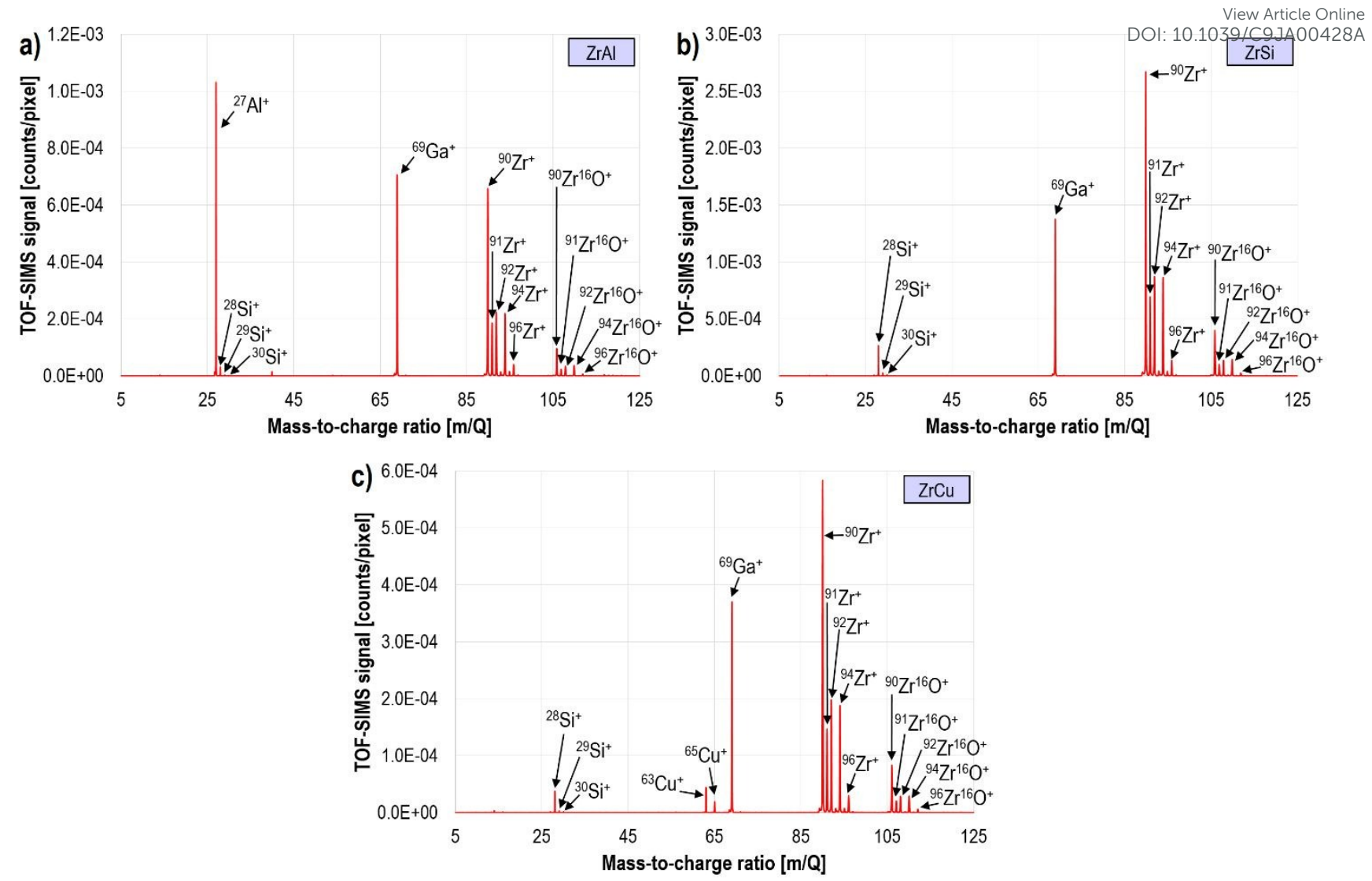

Figure 4. TOF-SIMS mass spectra of a) ZrAl, b) ZrSi and c) ZrCu. The most prominent ions present in the sample are identified.

Finally, the distributions of elements composing the alloys have to be homogenous in the entire thin film so that the ionisation process is also uniform within the studied volume. This can be validated using $2 \mathrm{D}$ elemental images representing ${ }^{90} \mathrm{Zr}^{+},{ }^{27} \mathrm{Al}^{+}$, ${ }^{28} \mathrm{Si}^{+}$and ${ }^{63} \mathrm{Cu}^{+}$signal distributions (Figure 5). Figure 5 a-f show top views (the lateral $x-y$ plane; signal averaging over frames, i.e. FIB scans) and Figure $5 \mathrm{~g}$-I present side views (in depth, i.e. $z-x$ plane; signal averaging over $y$ ). In the case of all thin films, the signals acquired in the lateral plane are uniform. No grains, material segregation or regions with higher signal concentration of any of the two alloy elements can be distinguished. Also no roughness or other topology effects potentially leading to the preferential FIB-sputtering are visible (which is consistent with FIB SE images shown in Figure 2). This indicates that during the sample preparation both elements were deposited properly. The side view images (Figure $5 \mathrm{~g}-\mathrm{I}$ ) show increased TOF-SIMS signals in the upper-most surfaces and on the interfaces between the thin films and the substrates in the case of all samples and all considered ions. This is most likely correlated with the surface (both, the thin film surface and the substrate surface) oxidation as it is known that oxygen enhances positive ion yields.

\section{TOF-SIMS depth profiles and calculations of total secondary ion signals}

The 2D TOF-SIMS imaging allows details of sample elemental composition to be represented whilst depth profiling delivers more global information (i.e. the signals are integrated over entire frames and are given as a function of the sputtering time) on the element distributions. The latter one is more useful when local signal variations are not important but the general tendency of the signal shape in depth matters.

The depth profiles of two-element thin films are shown in Figure 6. Although in theory two-element systems are considered, in practice much more elements are involved in the ionization process. On the side of the upper-most surface, the most crucial element is oxygen. Moreover, contaminants such as $\mathrm{H}, \mathrm{C}$ and $\mathrm{N}$ can be present as well. These elements are naturally present in the atmosphere and, therefore, it is hardly possible to avoid them on the sample fabrication stage. Besides that, a sample surface can be contaminated during the transportation to an analytical instrument. Although dedicated sample transfer systems are available on a market, their application in these studies would not change the situation due to operation in $\mathrm{HV}$ conditions. The $5 \mathrm{~nm}$ layer of protective $\mathrm{Au}$ coating is rather not expected to influence significantly the ionisation probability. Only in the central part of the thin films the dominant role in the ionisation efficiency is assigned to the interactions between the two metals ( $\mathrm{Zr}-\mathrm{Al}$ and $\mathrm{Zr}-\mathrm{Cu}$ ) or the metal and the metalloid ( $\mathrm{Zr}-\mathrm{Si})$. Regarding the interface between the thin film and the substrate, apart from oxygen additional influence on secondary ion generation can originate from the presence of $\mathrm{Si}$. The depth profiles presented in Figure 6 
TOP VIEWS

\section{ELEMENT 1}

a)

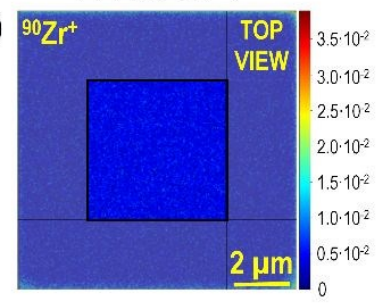

c)

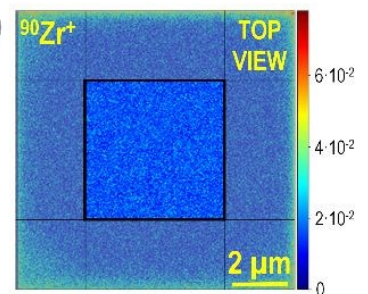

e)

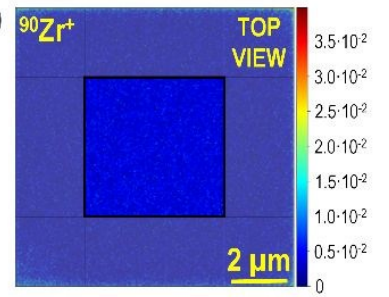

\section{b) 27} EL
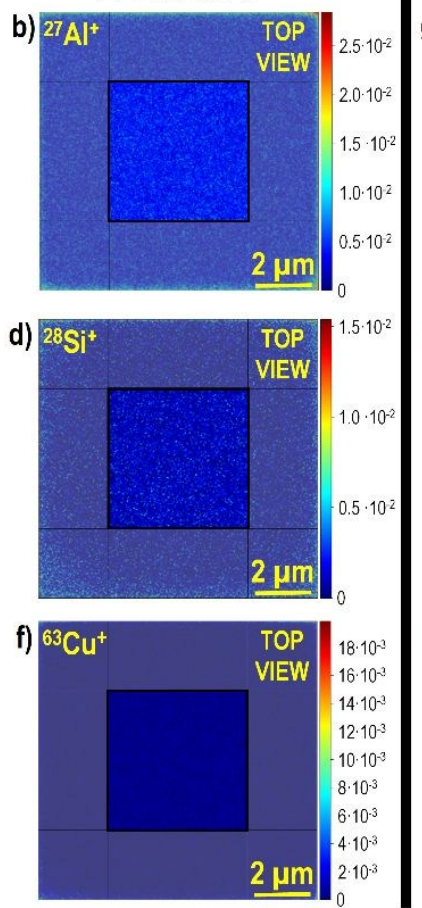

DOl: $10.1039 / C$

View Article Online

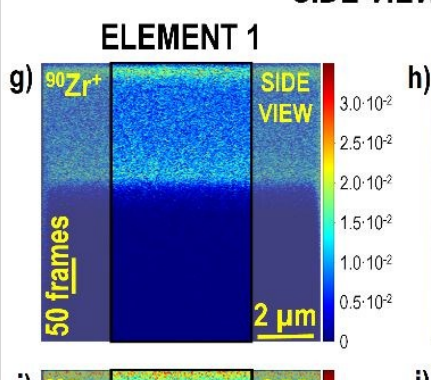

\section{ELEMENT 2}
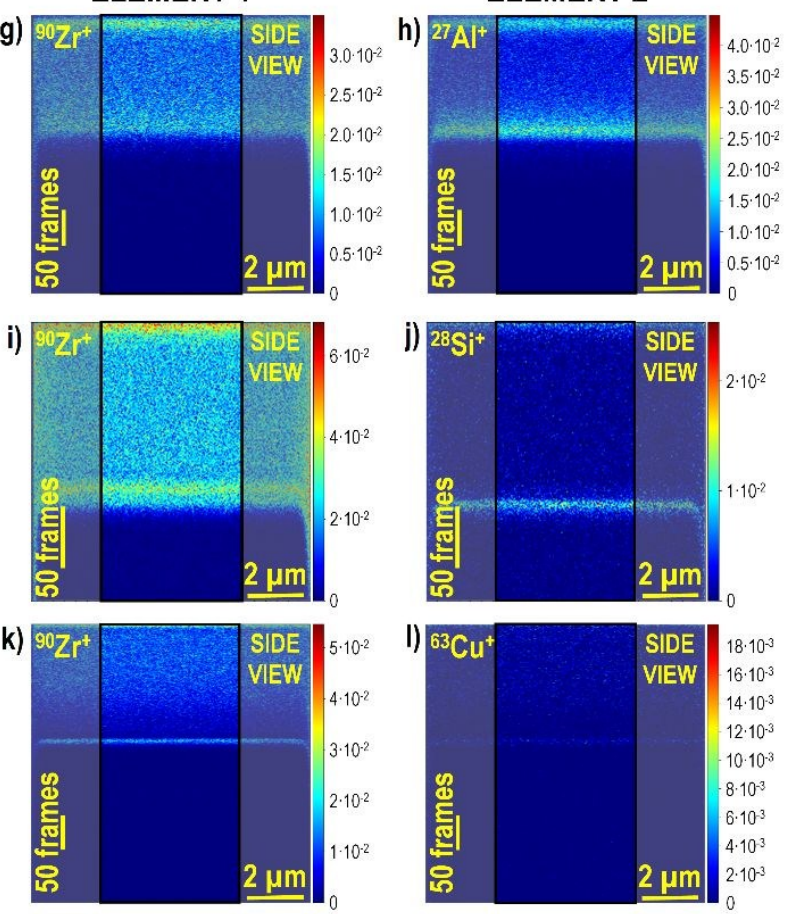

SIDE VIEWS

Figure 5. 2D elemental images representing ${ }^{90} \mathrm{Zr}^{+},{ }^{27} \mathrm{Al}^{+},{ }^{28} \mathrm{Si}^{+}$and ${ }^{63} \mathrm{Cu}^{+}$signal distributions. a-f) top views (i.e. $x-y$ plane), g-l) side views (i.e. $x$ - $z$ plane). The ROIs (Regions-Of-Interest) are bounded within the black rectangular boxes. were generated using only the central $5 \mu \mathrm{m} \times 5 \mu \mathrm{m}$ ROIs (Regions-Of-Interest, marked in Figure 5) to prevent the influence of edge effects (such as material re-deposition and smoothening of the crater edges). In the case of all measurements, the location of thin film-substrate interfaces can be well recognized based on the normalized distributions given in Figure 7. A cross-point between one of the thin film used as a moment of reaching the interface, $t_{\text {interface }}$. The errors, $\Delta t_{\text {interface, }}$ were obtained based on the positions of upper and lower cross points of signal envelopes.

All two-element alloys have two peaks in ${ }^{90} \mathrm{Zr}^{+}$signal distributions - one close to the sample surface and the other one close to the interface with the substrate. This is in contrast to the TOF-SIMS results of a pure $\mathrm{Zr}$ thin film in which only the surface peak appears ${ }^{8}$. This two-peak trend is also observed in ${ }^{27} \mathrm{Al}^{+},{ }^{28} \mathrm{Si}^{+}$and ${ }^{63} \mathrm{Cu}^{+}$signal distributions.

Moreover, a shift between signal peaks of thin film components occurs in the case of $\mathrm{ZrAl}$ sample. Although ${ }^{27} \mathrm{Al}^{+}$and ${ }^{90} \mathrm{Zr}^{+}$signal peaks in the upper most surface are recorded at the same time, the other signal peaks in these two ion distributions are shifted in the proximity to the substrate (by around 6 frames). This suggests different response of elements to the presence of Si. Such behaviour is not observed in the case of $\mathrm{ZrCu}$.

In the two-element alloys considered in this study, the total ionization efficiency (indirectly measured using TOF-SIMS signals) of $Z r$ is roughly the same as the ionization efficiency of Al (i.e. the total $\mathrm{Zr}$ secondary ion signal, $\mathrm{S}_{90 Z \mathrm{r}+}$, to the total signal distributions and the substrate signal distribution was

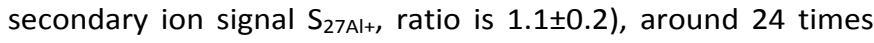
higher than the ionization efficiency of $\mathrm{Si}$ and about 15 times higher than the ionization efficiency of $\mathrm{Cu}$. However, it has to be remembered that these ratios most likely will be different (mainly due to matrix effect) when corresponding signals of pure metals are compared. Moreover, even slight modifications of alloy chemical composition can significantly affect the signal ratios.

Sputtering rates of the studied materials varied between $0.65 \pm 0.06 \mathrm{~nm} /$ frames (for ZrAl) and $1.09 \pm 0.09 \mathrm{~nm} /$ frames (for $\mathrm{ZrCu}$ ) for the applied parameters of ${ }^{69} \mathrm{Ga}^{+}$primary ion beam. The results of the experiments are summarized in Table 2 . The total TOF-SIMS signal of an element was calculated as an integral of signal distribution over the entire thin film thickness (based on the moment of reaching the interface with the substrate):

$$
S_{T O F-S I M S, \text { total }}=\int_{t_{\text {surface }}=0}^{t_{\text {interface }}} S_{\text {TOF-SIMS }}(t) d t .
$$

The TOF-SIMS signal errors were estimated using $\Delta t_{\text {interface. The }}$ errors of signal ratios were calculated using the exact differential:

$$
\frac{S_{90 Z r+}}{S_{x M+}}=\left|\frac{\partial\left(\frac{S_{90 Z r+}}{S_{x M+}}\right)}{\partial S_{90 Z r+}} \cdot \Delta S_{90 Z r+}\right|+\left|\frac{\partial\left(\frac{S_{90 Z r+}}{S_{x M+}}\right)}{\partial S_{x M+}} \cdot \Delta S_{x M+}\right| .
$$

Similarly, the errors of sputtering rates were obtained assuming $5 \%$ error in accuracy of sample thickness measurements with SEM. 
2

5

6

7

8

10

11
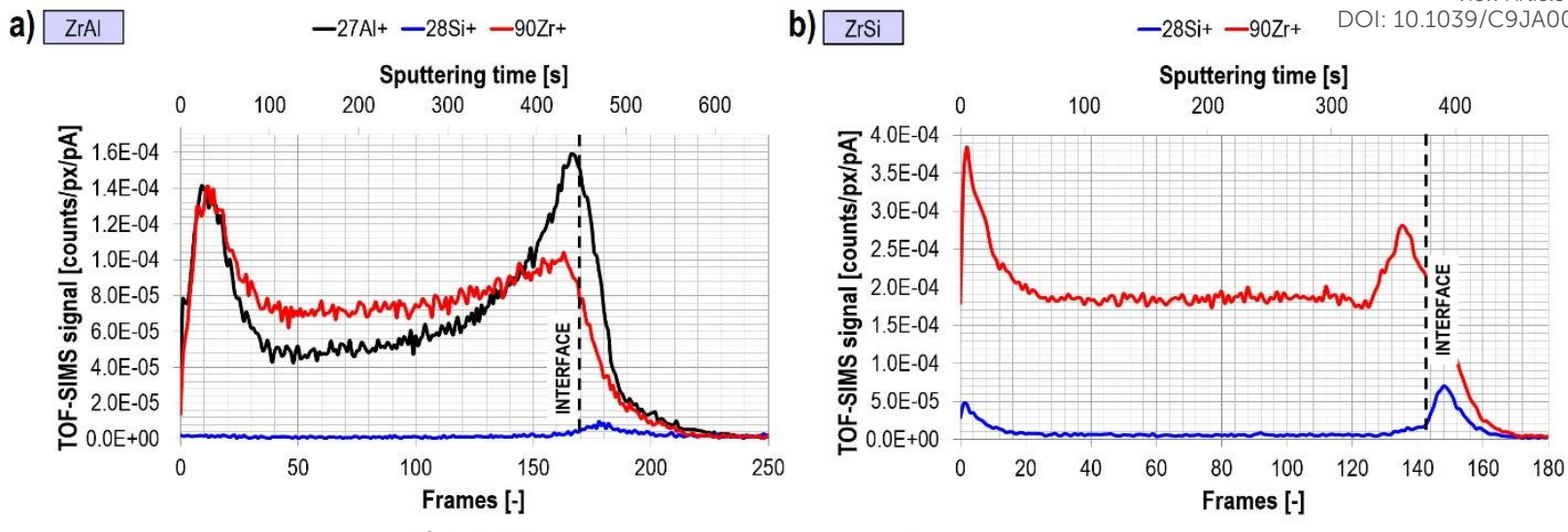

C) $\mathrm{ZrCu}$

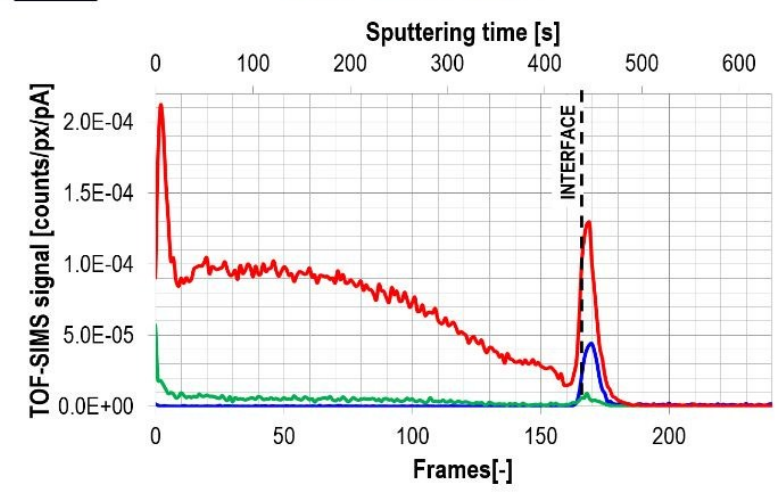

Figure 6. TOF-SIMS depth profiles of a) a ZrAl thin film, b) a ZrSi thin film and c) a ZrCu thin film. The data was acquired from the ROIs marked in Figure 5 (central $5 \mu \mathrm{m} \times 5 \mu \mathrm{m}$ ) and was normalized to 1 pA of impacting primary ion beam. The acquisition time of a single frame is around $2.64 \mathrm{~s}$.

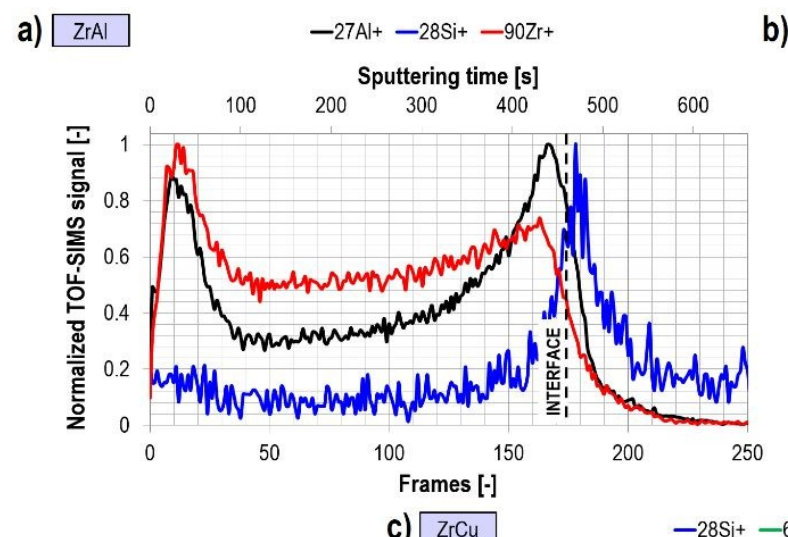

b) $\mathrm{ZrSi}$

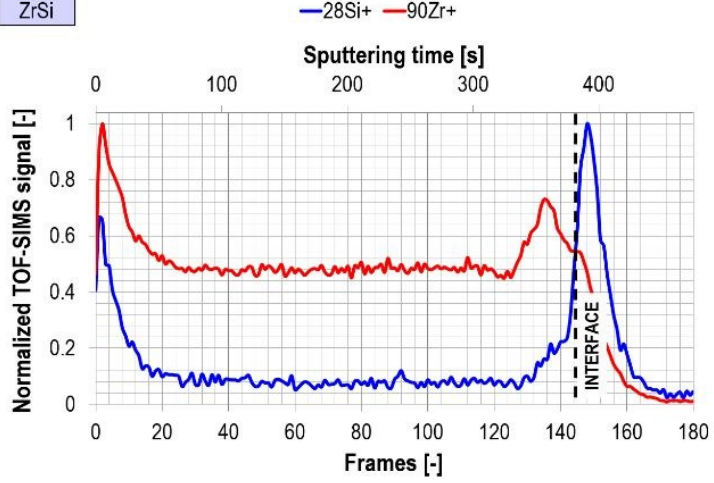

c) $\mathrm{ZrCu}$

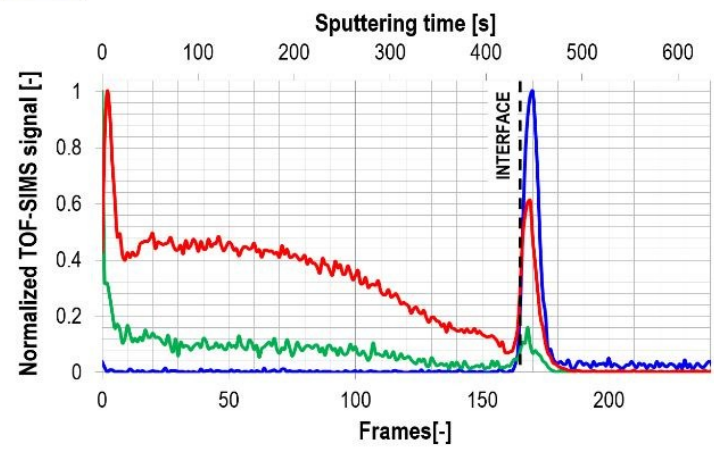

Figure 7. Normalized to 1 TOF-SIMS depth profiles of a) a ZrAl thin film, b) a ZrSi thin film and c) a ZrCu thin film. The data was acquired from the ROls marked in Figure 5 (central $5 \mu \mathrm{m} \times 5 \mu \mathrm{m}$ ). 


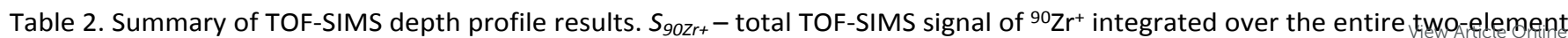

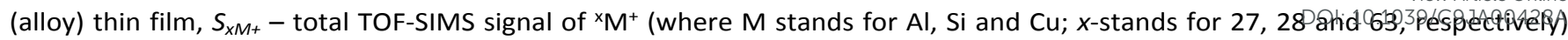
integrated over the entire two-element (alloy) thin film.

\begin{tabular}{|c|c|c|c|c|c|}
\hline Sample & Element & $t_{\text {interface }}[$ frames $]$ & $S_{T O F}-\operatorname{SIMS}$, total $[$ counts $/ \mathrm{px} / \mathrm{pA} / \mathrm{nm}]$ & $\frac{S_{90 Z r+}}{S_{x M+}}$ & Sputtering rate $[\mathrm{nm} /$ frame] \\
\hline \multirow{2}{*}{ ZrAl } & ${ }^{90} \mathrm{Zr}^{+}$ & \multirow{2}{*}{$173 \pm 5$} & $(1.28 \pm 0.04) \times 10^{-4}$ & \multirow{2}{*}{$1.1 \pm 0.2$} & \multirow{2}{*}{$0.65 \pm 0.06$} \\
\hline & ${ }^{27} \mathrm{Al}^{+}$ & & $(1.18 \pm 0.08) \times 10^{-4}$ & & \\
\hline \multirow{2}{*}{$\mathrm{ZrSi}$} & ${ }^{90} \mathrm{Zr}^{+}$ & \multirow{2}{*}{$126 \pm 2$} & $(2.9 \pm 0.2) \times 10^{-4}$ & \multirow{2}{*}{$24 \pm 2$} & \multirow{2}{*}{$0.71 \pm 0.06$} \\
\hline & ${ }^{28} \mathrm{Si}^{+}$ & & $(1.18 \pm 0.08) \times 10^{-5}$ & & \\
\hline \multirow{2}{*}{$\mathrm{ZrCu}$} & ${ }^{90} \mathrm{Zr}^{+}$ & \multirow{2}{*}{$164 \pm 4$} & $(6.8 \pm 0.3) \times 10^{-5}$ & \multirow{2}{*}{$15.1 \pm 0.7$} & \multirow{2}{*}{$1.09 \pm 0.09$} \\
\hline & ${ }^{63} \mathrm{Cu}^{+}$ & & $(4.6 \pm 0.2) \times 10^{-6}$ & & \\
\hline
\end{tabular}

a)

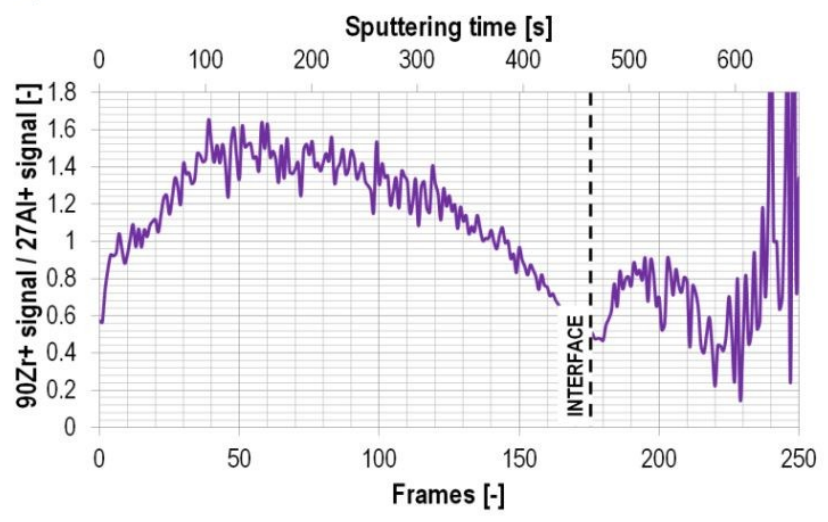

b)

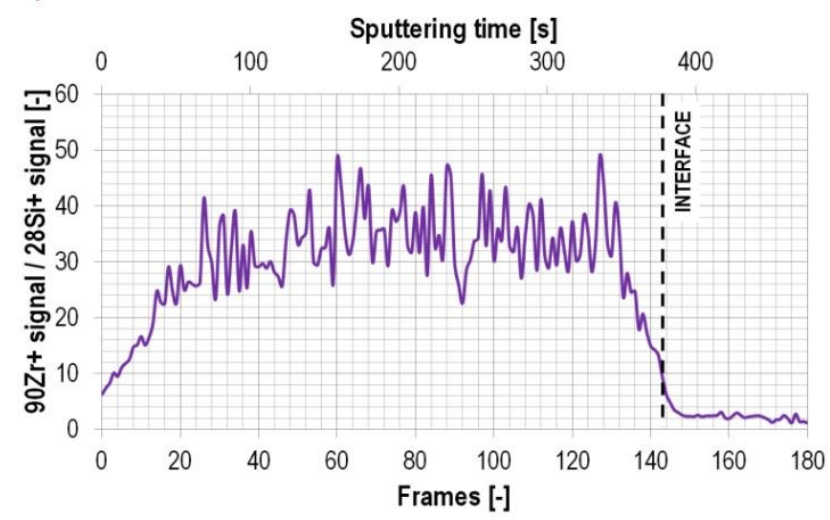

c)

$-90 \mathrm{Zr}+/ 63 \mathrm{Cu}+$

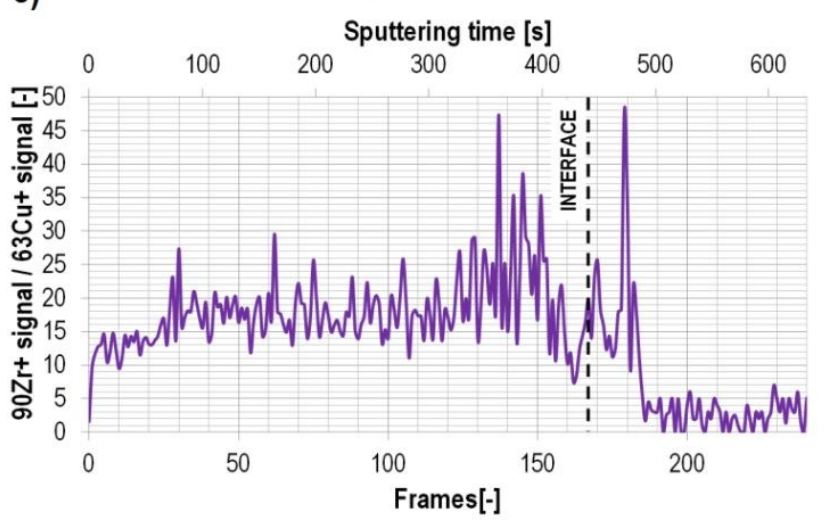

Figure 8. Ratios of a ${ }^{90} \mathrm{Zr}^{+}$signal and a ${ }^{27} \mathrm{Al}^{+}$signal (a), a ${ }^{28} \mathrm{Si}^{+}$signal (b), a ${ }^{63} \mathrm{Cu}^{+}$signal (c) as a function of sputtering time. The plots are based on the data presented in Figure 6.

The normalization of TOF-SIMS signal distributions (Figure 7) allows for better visualisation of the depth profile shapes. In all cases ${ }^{90} \mathrm{Zr}$ signals and the signals of the other element (i.e. ${ }^{27} \mathrm{Al}^{+}$, ${ }^{28} \mathrm{Si}^{+}$or $\left.{ }^{63} \mathrm{Cu}^{+}\right)$follow different patterns which rather excludes mass interference between them. In the case of $\mathrm{ZrAl}$ and $\mathrm{ZrSi}$, the TOF-SIMS signal peaks of ${ }^{27} \mathrm{Al}^{+}$and ${ }^{28} \mathrm{Si}^{+}$on the thin filmsubstrate interface are higher than those ones appearing on the sample surface, so the opposite to ${ }^{90} \mathrm{Zr}^{+}$signal peaks. Regarding ${ }^{27} \mathrm{Al}^{+}$this can indicate beneficial influence of Si presence on $\mathrm{Al}$ ion yields or a very narrow oxygen quantity window which maximizes the ionization efficiency. Directly from the TOF-SIMS data it is not possible to conclude on the size of the surface oxidation layer but, from the literature, it is known that silicon surface undergoes oxidation which saturates at the thickness of $0.1 \mathrm{~nm}$ (so called native silicon oxide) ${ }^{61}$. In fact, it was demonstrated that sometimes lower quantity of supplementary gas can lead to higher secondary ion signals $31,62,63$. Moreover, the TOF-SIMS data suggest that Si can have higher impact on ionization of $\mathrm{Al}$ than on the ionisation of $\mathrm{Zr}$. In the case of ${ }^{28} \mathrm{Si}^{+}$ the explanation of the two peak magnitude is more complex as in this case $\mathrm{ZrSi}$ alloy is deposited on a $<100>$ single crystal $\mathrm{Si}$ wafer. This means that most likely crystal orientations are different resulting in variation in SIMS sensitivities ${ }^{17}$. Besides that, it is also impossible to decompose the total ${ }^{28} \mathrm{Si}^{+}$signal to 
the component coming from the thin film and the component coming from the substrate. In the TOF-SIMS signals of $\mathrm{ZrCu}$ alloy, the peaks on the thin film-substrate interface are smaller than those ones on the sample surface for both, ${ }^{63} \mathrm{Cu}^{+}$and ${ }^{90} \mathrm{Zr}^{+}$. However, in the case of pure $\mathrm{Zr}$ and $\mathrm{Cu}$ thin films ${ }^{8}$ these peaks were not observed at all.

Figure 8 shows the distributions of ratios between ${ }^{90} \mathrm{Zr}^{+}$signals and the signals of the other alloy element $M$ (where $M$ stands for $\mathrm{Al}, \mathrm{Si}, \mathrm{Cu}$ ). On one hand, $\mathrm{Zr}$ ionization probability is dependent on the matrix of $\mathrm{M}$. At the same time, the generation of $\mathrm{M}^{+}$ions is influenced by the presence of $\mathrm{Zr}$. Moreover, they both are affected by other elements such as $\mathrm{O}, \mathrm{Si}, \mathrm{C}, \mathrm{H}$ and $\mathrm{N}$. If the responses of $\mathrm{Zr}$ and $\mathrm{M}$ to the surrounding (i.e. residual gas, surface contaminations and the species coming from the substrate) were the same, then the ratio of ${ }^{90} \mathrm{Zr}^{+}$signal to ${ }^{\times} \mathrm{M}^{+}$ signal ( $x$ stands for 27,28 and 63 for $\mathrm{Al}, \mathrm{Si}$ and $\mathrm{Cu}$, respectively) was invariant in time during the entire sputtering process. However, as presented in Figure 8, it is not the case for any of the considered alloys. The obtained data suggest that lighter elements (i.e. $\mathrm{Al}$ and $\mathrm{Si}$ ) are more sensitive to the presence of oxygen and probably $\mathrm{Si}$ (coming from the substrate) than the heavy elements ( $\mathrm{Cu}$ and $\mathrm{Zr}$ ).

\section{Conclusions}

The ionisation process of an element it determined by its individual capability of forming ions as well as its sensitivity to the sample chemical state, i.e. presence of other elements. The matrix effect can cause significant modifications in ionisation efficiency when comparing to the results obtained in the case of single element thins film. This concerns the total signal magnitude as well as the depth profile shape (i.e. sensitivity to boundary effects such as the presence of oxidized surface, surface contaminants or the proximity to the substrate). finding the most ionization-increasing combination of
Among the alloys considered in this study, the strongest influence on $\mathrm{Zr}$ ionisation process was induced by $\mathrm{Si}$. Over four times higher ${ }^{90} \mathrm{Zr}^{+}$secondary ion signal was recorded when compared to the results obtained with the $\mathrm{Cu}$ matrix and 2.2 higher in comparison with the values measured in Al matrix. Moreover, it was observed that the ionization efficiencies of the two alloy components vary along the thin film indicating different sensitivities to the boundary conditions. This shows that by enriching (or doping) certain materials an enhancement of ion yields can be achieved leading to higher TOF-SIMS spatial resolution. Therefore, studies on matrix effect (leading to elements) can be very beneficial for representing elemental distribution of materials in 3D space, in particular in the case of weakly ionizing elements. This can lead to pushing TOF-SIMS spatial resolution limits. Currently, the best lateral resolution lower than $20 \mathrm{~nm}$ was obtained with $\mathrm{Bi}_{3}$ clusters ${ }^{64}$. On the other hand, a Ga beam spot size can be as small as $2.5 \mathrm{~nm}$ at $1 \mathrm{pA}$ beam current 65,66 . Nevertheless, operating at such low currents in general does not find application in elemental characterization due to insufficient secondary ion count rate. Therefore, it is expected that the proper choice of model sample composition can maximize ion yields and minimize detection

1

limits of elements in the TOF-SIMS technique allowing for beating the lateral resolution record (howevie, the/diffepentes in evolution of collision events induced by $\mathrm{Ga}$ and cluster beams 67,68 have to be taken into account). This explains the need of more extended studies to fully understand the ionisation processes in inorganic and organic materials.

Apart from that, the presented results are expected to serve as the base for further exploring the potential of gas-assisted FIBTOF-SIMS ${ }^{8}$ elemental characterization. The mutual influence of atoms forming the two-element system had to be profoundly analysed in advance to judge on a gas influence on ion yield modifications (i.e. the gas-induced ion yield modification has to be distinguished from the sample matrix-induced ion yield changes).

\section{Conflicts of interest}

"There are no conflicts to declare".

\section{Acknowledgements}

The EMPAPOSTDOCS-II programme has received funding from the European Union's Horizon 2020 research and innovation programme under the Marie Skłodowska-Curie grant agreement number 754364 . The TOF-SIMS measurements have been performed in the frame of Swiss Commission for Technology and Innovation (CTI) project (no.: 25592.1 PFNMNM). The authors would like to express their gratitude to TOFWERK (Thun, Switzerland) for an access to the TOF-SIMS instrumentation.

\section{Notes and references}

A. Benninghoven, F. G. Werner and R. and H. W., Surf. Interface Anal., 1987, 10, 435.

P. Van de Heide, Secondary Ion Mass Spectrometry: An Introduction to Principles and Practices, 2014. A. Benninghoven, Surf. Sci., 1994, 299-300, 246-260. V. R. Deline, W. Katz, C. A. Evans and P. Williams, Appl. Phys. Lett., 1978, 33, 832-835.

B. Johansson, Surf. Interface Anal., 2006, 38, 1401-1412. S. Nakano, T. Yamagishi, S. Aoyagi, A. Portz, M. Dürr, H. Iwai and T. Kawashima, Biointerphases, 2018, 13, 03 B403. R. K. Lewis, J. M. Morabito and J. C. C. Tsai, Appl. Phys. Lett., 1973, 23, 260-262.

A. Priebe, I. Utke, L. Pethö and J. Michler, Anal. Chem., 2019, 91, 11712-11722.

Y. Gao, J. Appl. Phys., 1988, 64, 3760-3762.

Y. Gao, Y. Marie, F. Saldi and H. N. Migeon, Int. J. Mass Spectrom. Ion Process., 1995, 143, 11-18.

M. Inoue and A. Murase, Surf. Interface Anal., 2005, 37, 1111-1114.

A. M. Alnajeebi, S. Sherez (nee Rabbani), J. C. Vickerman and L. N. P., in Proceedings of the Eighth Saudi Students Conference in the UK, eds. N. Alford and J. Frechet, Imperial Collegue Press, London, 2006, pp. 437-444. 
B. J. Tyler, G. Rayal and D. G. Castner, Biomaterials, 2007, 28, 2412-2423.

I. T. Jolliffe, Principal Component Analysis, Springer-Verlag New York, New York, 2nd edn., 2002.

12

16 P. J. Cumpson, N. Sano, I. W. Fletcher, J. F. Portoles, M. Bravo-Sanchez and A. J. Barlow, Surf. Interface Anal., 2015, 47, 986-993.

17 J. C. Vickermann and D. Briggs, ToF-SIMS: Materials Analysis by Mass Spectrometry, IM Publications LLP, West Sussex, United Kingdom, 2nd edn., 2013.

18 A. Priebe, G. Audoit and J. P. Barnes, Ultramicroscopy, 2017, 173, 10-13.

19 S. Sheraz, A. Barber, J. S. Fletcher, N. P. Lockyer and J. C. Vickerman, Anal Chem, 2013, 2-3.

20 S. Sheraz, A. Barber, I. B. Razo, J. S. Fletcher, N. P. Lockyer and J. C. Vickerman, Surf. Interface Anal., 2014, 46, 51-53. S. Sheraz Née Rabbani, I. B. Razo, T. Kohn, N. P. Lockyer and J. C. Vickerman, Anal. Chem., 2015, 87, 2367-2374.

A. Wucher, Appl. Surf. Sci., 2006, 252, 6482-6489.

S. Ghalab and A. Wucher, Nucl. Instruments Methods Phys. Res. Sect. B Beam Interact. with Mater. Atoms, 2004, 226, 264-273.

A. Priebe, L. Pethö and J. Michler, Anal. Chem., , DOI:10.1021/acs.analchem.9b04647.

M. Bernheim and F. Le Bourse, Nucl. Inst. Methods Phys. Res. B, 1987, 27, 94-103.

M. Bernheim and G. Slodzian, J. Phys. Lettres, 1977, 38, 325-328.

V. E. Krohn, J. Appl. Phys., 1962, 33, 3523-3525.

H. A. Storms, K. F. Brown and J. D. Stein, Anal. Chem., 1977, 49, 2023-2030.

T. Wirtz and H. N. Migeon, Surf. Sci., 2004, 561, 200-207.

K. Wittmaack, Surf. Sci. Rep., 2013, 68, 108-230.

A. Priebe and J. Michler, Ultramicroscopy, 2019, 196, 1017.

V. R. Deline, C. A. Evans and P. Williams, Appl. Phys. Lett., 1978, 33, 578-580.

K. Wittmaack, J. Appl. Phys., 1981, 52, 527-529.

P. Williams, V. R. Deline, C. A. Evans and W. Katz, J. Appl. Phys., 1981, 52, 530-532.

P. Williams, Surf. Sci., 1979, 90, 588-634.

W. H. Wang, C. Dong and C. H. Shek, Mater. Sci. Eng. $R$ Reports, 2004, 44, 45-90.

J. F. Löffler, Intermetallics, 2003, 11, 529-540.

E. Axinte, Mater. Des., 2012, 35, 518-556.

W. H. Wang, Prog. Mater. Sci., 2012, 57, 487-656.

M. M. Trexler and N. N. Thadhani, Prog. Mater. Sci., 2010, 55, 759-839.

A. Priebe, J.-P. Barnes, T. E. J. Edwards, L. Pethö, I. Balogh and J. Michler, Anal. Chem., 2019, 91, 11834-11839.

M. Hosokawa, K. Nogi, M. Naito and T. Yokoyama,

Nanoparticle Technology Handbook, 2012.

A. L. Greer, Y. Q. Cheng and E. Ma, Mater. Sci. Eng. $R$ Reports, 2013, 74, 71-132.

T. C. Hufnagel, C. A. Schuh and M. L. Falk, Acta Mater.,
2016, 109, 375-393.

View Article Online

C. Suryanarayana and A. Inoue, BulkMletalliezelasses, CRRA Press, Boca Raton, 2011.

C. L. Qiu, Q. Chen, L. Liu, K. C. Chan, J. X. Zhou, P. P. Chen and S. M. Zhang, Scr. Mater., 2006, 55, 605-608.

N. Bin Hua, R. Li, J. F. Wang and T. Zhang, Sci. China Physics, Mech. Astron., 2012, 55, 1664-1669.

T. Wada, F. Qin, X. Wang, M. Yoshimura, A. Inoue, N. Sugiyama, R. Ito and N. Matsushita, J. Mater. Res., 2009, 24, 2941-2948.

L. Huang, C. Pu, R. K. Fisher, D. J. H. Mountain, Y. Gao, P. K. Liaw, W. Zhang and W. He, Acta Biomater., 2015, 25, 356368.

L. Manchanda, M. L. Green, R. B. Van Dover, M. D. Morris, A. Kerber, Y. Hu, J. Han, P. J. Silverman, T. W. Sorsch, G.

Weber, V. Donnelly, K. Pelhos, F. Klemens, N. A. Ciampa, A. Kornblit, Y. Kim, J. E. Bower, D. Barr, E. Ferry, B.

Laboratories, L. Technologies and M. Hill, Int. Electron Devices Meet. 2000. Tech. Dig. IEDM (Cat. No.00CH37138), 2000, 23-26.

R. j. Baker, CMOS: Circuit Design, Layout, and Simulation, Wiley \& Sons, Inc, Hoboken, NJ, USA, 3rd edn., 2010. Y. Saotome, S. Miwa, T. Zhang and A. Inoue, J. Mater. Process. Technol., 2001, 113, 64-69. G.-H. Mohamed, MEMS: Design and Fabrication, CRC Press, Boca Raton, 2005.

Y. Li, J. Zhu, H. Liu and Z. Liu, Microelectron. Eng., 2006, 83, 1905-1911.

Mater. Sci., 2014, 82, 70-75.

Q. An, K. Samwer, W. A. Goddard, W. L. Johnson, A. Jaramillo-Botero, G. Garret and M. D. Demetriou, J. Phys. Chem. Lett., 2012, 3, 3143-3148.

G. Binning, F. Quate and C. Gerber, Phys. Rev. Lett., 1986, 56, 930-933.

L. Reimer, Scanning Electron Microscopy: Physics of Image Formation and Microanalysis, Springer-Verlag Berlin Heidelberg, 2nd edn., 1998. K. S. Sree Harsha, Princ. Vap. Depos. Thin Film., , DOI:10.1016/B978-008044699-8/50005-X.

B. Nicolas, H. Demers and R. Gauvin, Field Emission Scanning Electron Microscopy: New Perspectives for Materials Characterization, Springer, Singapore, 2007. M. Morita, T. Ohmi, E. Hasegawa, M. Kawakami and M. Ohwada, J. od Appl. Phys., 1990, 68, 1272-1281. Negat. Hydrog. Ions Beams, 1980, 126.
J. Ishikawa, in The Physics and Technology J. Ishikawa, in The Physics and Technology of Ion Sources, ed. Ian G. Brown, Wiley-VCH Verlag GmbH \& Co. KGaA, 2nd edn., 2005, pp. 285-310.

F. Kollmer, W. Paul, M. Krehl and E. Niehuis, Surf. Interface Anal., 2013, 45, 312-314. R. A. Fleck and B. M. Humbel, Biological Field Emission Scanning Electron Microscopy, John Wiley \& Sons, INC., West Sussex, United Kingdom, 2019. Orsay Physics, Technical Sheet of 'Cobra The wellrecognized Ga FIB column', 
http://www.orsayphysics.com/upload/1466673230.pdf, (accessed 19 March 2019).

67 N. Winograd, Annu. Rev. Anal. Chem., 2018, 11, 29-48.

68 Z. Postawa, B. Czerwinski, M. Szewczyk, E. J. Smiley, N. Winograd and B. J. Garrison, J. Phys. Chem. B, 2004, 108, 7831-7838. 